Research Article

\title{
Simulation of the Effect of Coal Microstructures on the Macroscopic Mechanical Behavior
}

\author{
Yu Fu $\mathbb{D}^{1,2}$ and Zhongliang Feng ${ }^{1,2}$ \\ ${ }^{1}$ State Key Laboratory for Geomechanics and Deep Underground Engineering, China University of Mining and Technology, \\ Beijing 100083, China \\ ${ }^{2}$ School of Mechanics and Civil Engineering, China University of Mining and Technology, Beijing 100083, China
}

Correspondence should be addressed to Yu Fu; tbp1600601006@student.cumtb.edu.cn

Received 16 January 2020; Revised 26 August 2020; Accepted 11 November 2020; Published 26 November 2020

Academic Editor: Xuemei Liu

Copyright ( $2020 \mathrm{Yu} \mathrm{Fu}$ and Zhongliang Feng. This is an open access article distributed under the Creative Commons Attribution License, which permits unrestricted use, distribution, and reproduction in any medium, provided the original work is properly cited.

\begin{abstract}
This paper investigates the influence of mineral structure on macromechanical behavior of coal under different loading conditions using X-ray CT scanning experimental and numerical methods. The three-dimensional (3D) reconstruction of coal was conducted to assess the spatial distribution characteristics of the mineral structure by AVIZO software. Based on fractal box dimension (BCD) and equivalent diameter, the mineral structures were quantitatively characterized. The 3D finite element models with three distribution characteristics of minerals were built, and the model was considered as a random heterogeneous two-phase material composed of coal matrix and mineral matter. The results show that the frequency of mineral structures decreases with the increase of equivalent diameter in the coal sample. The BCD of the original mineral structure in coal is greater than 2, but the $\mathrm{BCD}$ of each part of the minerals divided based on the screening principle is less than 2. Under uniaxial conditions, the elastic modulus, peak strength, and residual strength of coal are monotonically increasing with the size of the mineral structure. The larger the mineral structure size and the more complex the distribution are, the greater the area of stress concentration and the more uniformity the distribution will be. The failure (plasticity) first occurred at the interface between the matrix and the mineral, and the failure zone is significantly different due to the influence of different mineral structures. Under confining pressure, the presence of mineral structure decreases the brittleness of coal, and the variation of brittleness is related to the size and spatial distribution of mineral structures. The fitting relationship between confining pressure and brittleness index is linear, and the correlation coefficient exceeds 0.95 .
\end{abstract}

\section{Introduction}

As a kind of natural complex geological material, coal is a combination of many components, including coal matrix, micropores, fractures, and minerals $[1,2]$. The spatial distribution of these components forms and controls the microstructure of coal and is determined by the biological coalification process and geological history of the coal formation. The microstructure characteristics of coal components have a direct influence on macroscopic mechanical behavior under load. The research shows that the variability of microstructure parameters (e.g., sizes, shapes, volume, and distribution) of mineral phases and microdefects is the main reason for inhomogeneous, anisotropic, and nonlinear elastic behavior of coal mechanics [3]. In addition, the key microstructure parameters of different mineral structures were generally believed to play major roles in influencing the deformation and failure behavior of coal. In recent years, the research on the relationship between the characteristics of microstructure and the macrofailure mechanisms of coal has become a popular topic $[4,5]$.

$\mathrm{X}$-ray computed tomography (X-ray $\mathrm{CT})$ technology is a noninvasive and nondestructive detection technique that is broadly used in rocks and other complex materials [6-8]. Over the past several years, based on the CT technique, many researchers conducted a great deal of research on the microstructure of coal. This technique has been used in the determination of mineral grouping and distribution of 
different rank coals; transitions with combustion, devolatilization, and gasification; shrinking and fracturing accompanying drying; fracturing during handling; the distribution of minerals and fractures at different depths; cleat spacing, cleat aperture and cleat system characterization, and cleat transitions during fluid flow and temperature change; fractures induced with impacts and microwave bursts; prediction and evaluation of permeability; among others [9-13]. The digital images' information obtained by $\mathrm{X}$-ray CT is particularly suitable for quantitative descriptions heterogeneities of the interior complex structures of coalrocks with high resolution [14]. The combination of the $\mathrm{X}$-ray CT image and $3 \mathrm{D}$ digital rock reconstruction algorithms provides an effective tool for studying the distribution of the microstructure of coal and its influence on the macroscopic mechanical behavior.

The finite element method (FEM) combined with $\mathrm{X}$-ray CT-based modeling is a powerful way to study the microstructure and mechanical properties of the heterogeneous materials $[15,16]$. In regard to the finite element model based on the digital image, $\mathrm{Xu}$ et al. [17] study the mechanical properties of rock based on the technique of digital image processing (DIP) and the FEM. Huang et al. [18] verified the $3 \mathrm{D}$ damage evolution process of concrete and used a 3D digital image and FE fracture modeling. Yue et al. [19] made a mechanical analysis of geotechnical materials by using the DIP-FE method, on the basis of considering their inhomogeneity and microstructure. Zhang and Toksöz [20] compute the elastic properties of sandstone using the FEM and 3D microtomographic images. The $3 \mathrm{D}$ numerical image-based FE model is a combination of three-dimensional reconstruction technology and numerical analyses method that is based on $\mathrm{X}$-ray CT technology. The establishment of a numerical model based on realistic microstructures of coal provides a new idea for the study of heterogeneity.

Previous studies focused on the response of coal heterogeneity to different external factors. For example, the influence of coal microstructure on mechanical properties is considered based on different loading rates and loading directions. However, there are still many inadequacies in the study of the difference in the internal structure of coal, especially the effect of real structure distribution on macroscopic mechanical behavior, which needs to be further studied.

In this paper, coal is regarded as a heterogeneous material composed of coal matrix and mineral. Firstly, $\mathrm{X}$-ray CT was used to scan the coal, and then the threedimensional reconstruction and quantitative characterization of the mineral structure in the coal was conducted by AVIZO software, and the distribution characteristics of minerals in the three-dimensional space were analysed. Based on digital image processing and finite element model, a three-dimensional (3D) finite element model with different mineral distributions was established. The effects of different mineral structures on the stress distribution and failure behavior (plastic distribution) of coal were studied by simulation under uniaxial compression. By introducing the brittleness index, the influence of minerals on brittleness characteristics of coal and rock under confining pressure is analysed, and the relation between confining pressure and brittleness index is fitted.

\section{Coal Sample and CT Scanning}

2.1. Coal Sample. The coal blocks used in this study were taken from the 21304 working face of the Chenjiao Coal Mine, located in Yongchen City, Henan Province, China. This coal seam is buried at a depth of approximately $900 \mathrm{~m}$. The coal is mainly composed of bright and specular coal, which belongs to a semibright type. A standard cylinder specimen is drilled from an original coal block and the specimen with a diameter of $50 \mathrm{~mm}$ and a height of $100 \mathrm{~mm}$, as shown in Figure 1(a). Figure 1(b) shows three cross sections of the coal sample, which are $X Y, Y Z$, and $X Z$ planes, respectively. To obtain the mineral composition of the coal, $\mathrm{X}$-ray diffraction (XRD) was adopted to determine the whole rock and clay mineral compositions for the high-density substance (bright zone) of coal, as shown in Figure 2(a). The $\mathrm{XRD}$ results showed that the coal specimens are mainly composed of calcite, the content is approximately $65.31 \%$, followed kaolinite, dolomite, illite, amorphous, and quartz, with relative contents of $11.5 \%, 10.9 \%, 6.19 \%, 5 \%$, and $1.1 \%$, respectively. The total content of clay minerals, such as illite and kaolinite, is $17.69 \%$, as shown in Figures 2(b) and 2(c).

2.2. X-Ray CT Scanning Tests. In this paper, to obtain the realistic structure information of coal, the X-ray CT scanning of the coal specimen was conducted using the X-ray 3D microscope (Nano Voxel-4000, Sanying Precision Instruments Co., Ltd., Tianjin, China), as shown in Figure 3. The spatial resolution of the scanner is $27 \mu \mathrm{m}$ and the magnification factor is 4.6. The coal sample was scanned with a current of $150 \mu \mathrm{A}$ and a voltage of $150 \mathrm{kV}$. Finally, the digital coal body with a voxel size of $865 \times 865 \times 1714$ pixels was obtained. The photograph of the scanned slices in the specimen is shown in Figure 4(a).

\section{Quantitative Characterization of Mineral Structure}

To reduce the data processing time and calculation load induced by oversized data in mesh analysis, a $10 \times 10 \mathrm{~mm}$ rectangular region of interest (ROI) was cropped from the CT image, as shown in Figure 4(a). Figure 4(b) shows crosssectional images obtained using computed tomography. The volume of the selected coal cube is $10 \mathrm{~mm} \times 10 \mathrm{~mm} \times 10 \mathrm{~mm}$. For a CT grayscale image, each pixel corresponds to a specific grayscale. Based on the difference of gray-scale value between mineral and matrix, the mineral can be separated from the matrix by threshold segmentation and binarization (pores and cracks were not considered). In this study, the "Unimodal Thresholding" algorithm was used to perform the same processing on each CT slice [21]. Figure 4(c) shows the mineral image after threshold segmentation. The processed image data was imported into AVIZO software for $3 \mathrm{D}$ reconstruction and analysis. Figure $4(\mathrm{~d})$ displays the mineral 


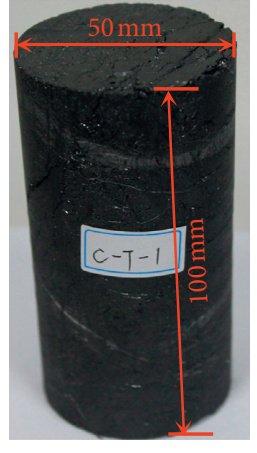

(a)

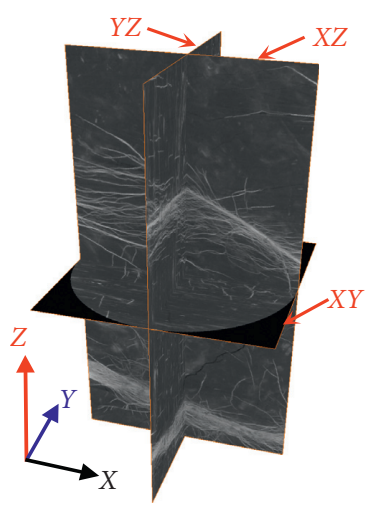

(b)

FIGURE 1: Coal specimens used in this study: (a) raw coal sample and (b) three orthogonal cross sections of the coal sample.

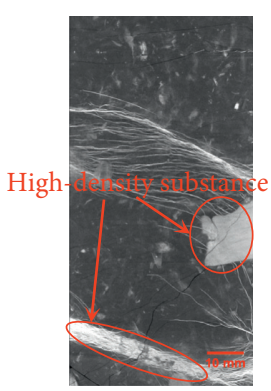

(a)

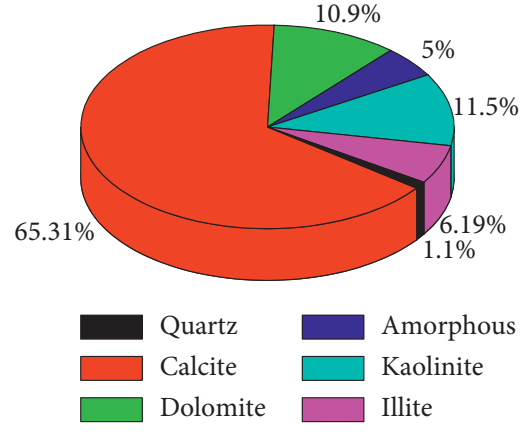

(b)

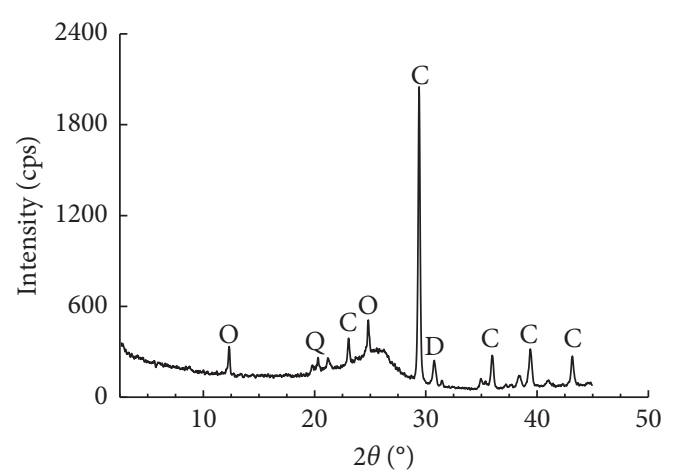

$\begin{array}{ll}\text { C-Calcite } & \text { D-Dolomite } \\ \text { Q-Quartz } & \text { O-Others }\end{array}$

(c)

FIGURE 2: Mineral composition analysis: (a) samples for XRD test (white area); (b) whole rock and clay mineral compositions; and (c) XRD curve of the coal.

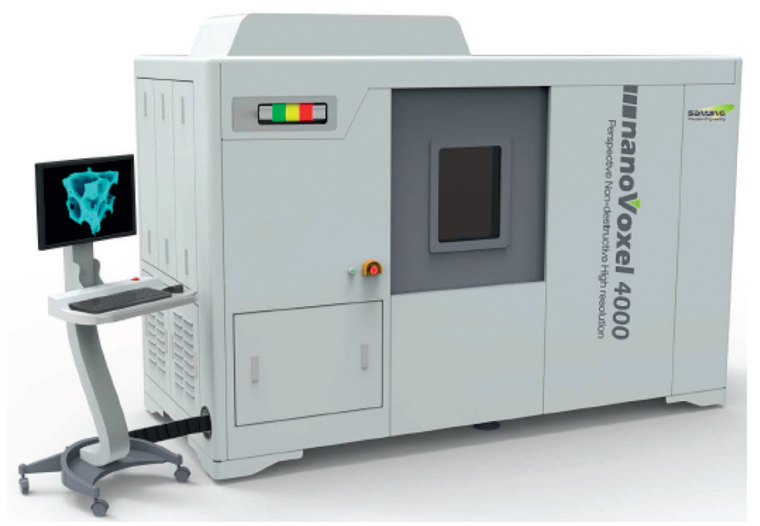

FIgURE 3: X-ray 3D microscope (NanoVoxel-4000).

structure distribution of coal (numbers: AL) after the $3 \mathrm{D}$ reconstruction.

In order to quantitatively analyse the spatial distribution of mineral structure, the parameter of equivalent diameter is introduced to measure the mineral size. The equivalent diameter is an important parameter for quantifying the irregular structure. Usually, the independent and irregular mineral structure is regarded as a sphere with the same volume, and the equivalent diameter can be obtained from the volume of the sphere.

According to the range of equivalent diameters, the mineral structure can be classified into three categories: $A 1$ ( $<500 \mu \mathrm{m}$ in diameter), $A 2(500-1500 \mu \mathrm{m}$ in diameter), and A3 $(>1500 \mu \mathrm{m}$ in diameter), respectively, as shown in Table 1. The $A 1, A 2$, and $A 3$ are obtained from $\mathrm{AL}$ according to the sieving principle. Figures $4(\mathrm{e})-4(\mathrm{~g})$ show the $3 \mathrm{D}$ spatial distribution of $A 1, A 2$, and $A 3$, which represent three mineral structures with different sizes, volumes, and distributions. Combined with the relevant calculation parameters of the mineral structure in Table 1, it can be clearly seen that the number of minerals is large and the volume is small, and the distribution is uniform in $A 1$; the minerals in $A 2$ are partially aggregated to form a larger volume structure; and the minerals in $A 3$ present a clusterlike structure with a small number and a large volume.

Figure 5 shows the frequency histograms and cumulative percent passing curves of the mineral structure. The number of mineral structures decreased with the increase of 


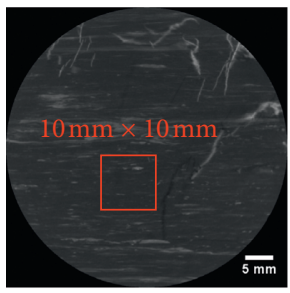

(a)

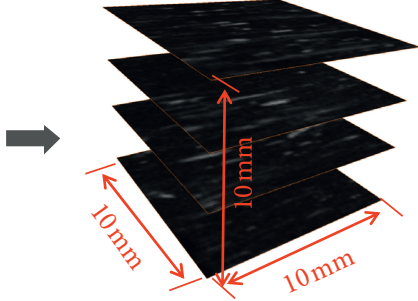

(b)

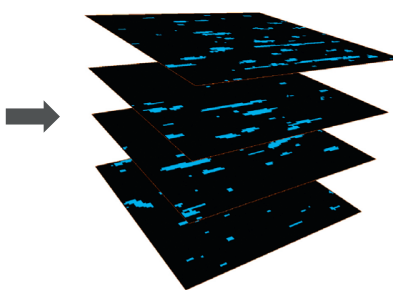

(c)

(d)
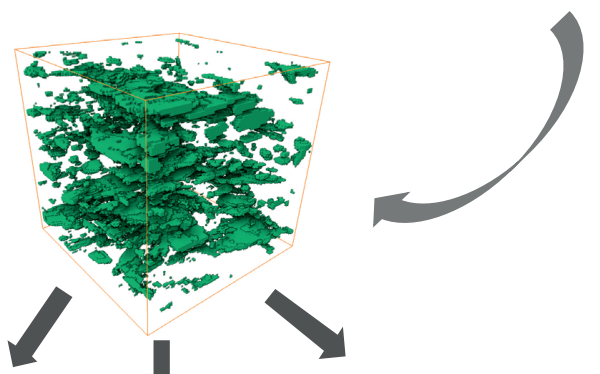

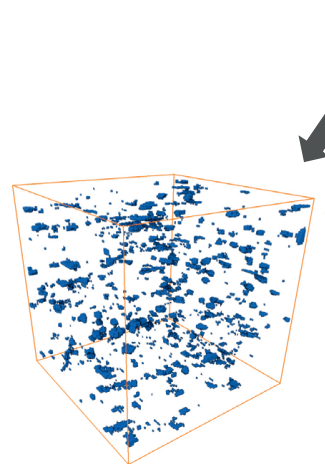

(e)

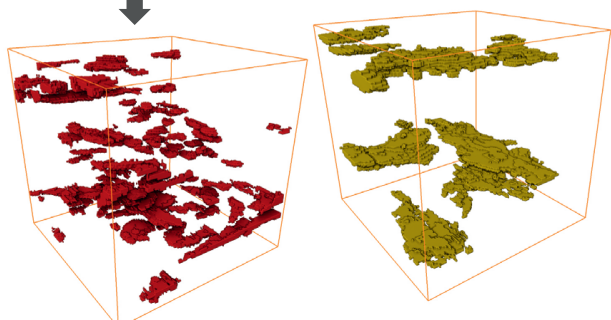

(f)

(g)

Figure 4: 3D reconstruction of mineral. (a) CT image. (b) Cross-sectional images. (c) Threshold segmentation. (d) 3D reconstruction of mineral inclusion by Avizo. (e, $\mathrm{f}$, and $\mathrm{g}$ ) The minerals with different equivalent diameters. From left to right, the equivalent diameters are $A 1$ $(<500 \mu \mathrm{m}), A 2(500-1500 \mu \mathrm{m})$, and $A 3(>1500 \mu \mathrm{m})$.

TABLE 1: Quantitative characterization of mineral in coal specimens.

\begin{tabular}{lcccc}
\hline Number & $\begin{array}{c}\text { Diameter } \\
(\mu \mathrm{m})\end{array}$ & Count & $\begin{array}{c}\text { Volume } \\
\left(\mu \mathrm{m}^{3}\right)\end{array}$ & $\begin{array}{c}\text { Fractal } \\
\text { dimension }\end{array}$ \\
\hline $\mathrm{AL}$ & - & 788 & $5.94 \times 10^{10}$ & 2.1687 \\
$\mathrm{~A} 1$ & $<500$ & 697 & $5.77 \times 10^{9}$ & 1.7284 \\
$\mathrm{~A} 2$ & $500-1500$ & 83 & $2.22 \times 10^{10}$ & 1.9449 \\
$\mathrm{~A} 3$ & $>1500$ & 8 & $3.15 \times 10^{10}$ & 1.9907 \\
\hline
\end{tabular}

equivalent diameter. When the equivalent diameter is in a small range, the cumulative percentage curve changes significantly, indicating that the contribution of the mineral structure with small diameter to the total volume is small. We characterized the mineral in volume and count with the label analysis module in AVIZO, and the results are listed in Table 1.

Fractal theory can effectively describe the inherent regularity of many irregular things in nature. It shows its unique application prospect in many fields such as biology, physics, astronomy, economics, geotechnical engineering, and computer graphics $[22,23]$. To clarify the heterogeneity of coal microstructure, understanding the complexity of mineral in coal is essential. In general, the fractal dimensions were used to characterize the mineral and fracture. There are many ways to define the fractal dimension. In this study, the

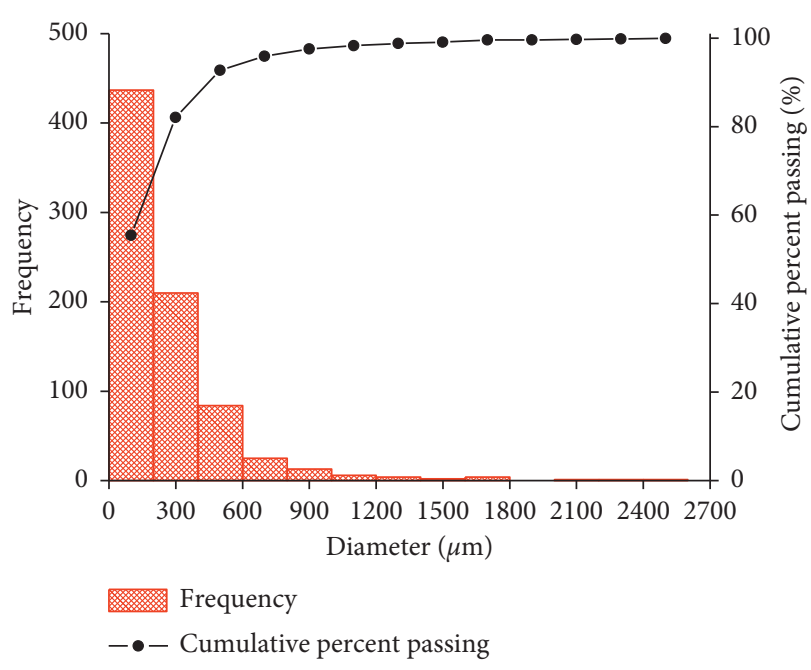

Figure 5: Combined histograms and cumulative percent passing curves for mineral.

self-similar fractal dimension, also known as the boxcounting dimension (BCD), is adopted. Defining the cube boxes with an edge length of $d$. By reducing the side length of the boxes by half, the total number of boxes $N(d)$ containing mineral can be counted. According to the previous definition, a log-log plot composed of the number of the boxes 
$N(d)$ versus the different sizes of boxes can be plotted; the slope of the linear fitting is the box dimension $(D)$ of mineral. The calculation formula is as follows [24]:

$$
D=\frac{\lg N(d)}{\lg d}
$$

where $d$ is the box size, $N(d)$ is the number of boxes, $D$ is the $\mathrm{BCD}$. The higher the value of $D$, the more complex the mineral distribution. After processing the CT gray-scale image, the BCD were calculated by MATLAB software, and the results are summarized in Table 1. Figure 6 shows the fractal dimension and volume fraction of different mineral structures, it can be seen that the order of mineral complexity is $\mathrm{AL}>A 3>A 2>A 1$. In general, the original mineral structure in coal satisfies the three-dimensional fractal feature, and its fractal dimension is between 2 and 3 . In Table 1, the fractal dimension of AL is greater than 2, indicating that the mineral distribution in coal is consistent with 3D fractal characteristics, while the fractal dimension of $A 1, A 2$, and $A 3$ separated from $\mathrm{AL}$ is less than 2 , which illustrates that the original mineral structure is grouped by the sieving principle and the original distribution of the structure will be disturbed, so that the fractal dimension of each part after grouping will be less than 2 . The change of mineral distribution makes it no longer conform to the three-dimensional fractal characteristics.

\section{Numerical Model Establishment}

4.1. Image-Based FE Model Generation. In order to facilitate the finite element analysis, some scholars have tried a new method to build geometric model $[3,25]$. In this paper, a series of two-dimensional (2D) CT images, including mineral and coal matrix, was imported into Mimics (Materialize Inc., France) at first and then was reconstructed and meshed. The meshing on the surface and its optimization and the volume mesh generation were conducted in 3-matic software. The coal sample was divided into two types of material based on different gray values, namely, coal matrix and mineral inclusions, as is shown in Figure $7(\mathrm{~b})$. The 3-matic software is used to improve surface mesh and generate tetrahedral mesh. The tetrahedral mesh of the mineral inclusions and the coal matrix were directly exported to ABAQUS FEA; then, the finite element model was established, as shown in Figure $7(\mathrm{c})$. The finite element model was assigned boundary conditions to simulate different stress states. The specific modeling process is illustrated in Figure 7.

According to the above method, the finite element mesh model of coal containing $A 1, A 2$, and $A 3$ mineral distribution is established, as shown in Figure 8. In order to reduce the errors caused by meshing, a total of 73636 elements were ultimately obtained and established, and the three models have the same number of elements. In the process of modeling, the interface between mineral and coal matrix is realized by coupling two parts to form a common surface.
4.2. Estimations of Material Properties. It is difficult to mesh and calculate the model when the pores and microcracks are considered. Therefore, in the numerical simulation of this paper, it is assumed that the coal body is composed of coal matrix and mineral. The mineral density of coal is much higher than that of the coal matrix, and it is easy to distinguish them by CT. In this paper, the basic mechanical properties of coal matrix and minerals are estimated by referring to the experimental data of Zhao et al. [25], and the approximate values of each basic physical and mechanical parameter of numerical simulation are given, as shown in Table 2.

In this paper, the Mohr-Coulomb and strain-softening constitutive models in ABAQUS are used for the numerical modeling, and the different material properties are assigned to the coal matrix and the mineral. Macroscopically, the numerical models of coal are regarded as anisotropic, but for the coal matrix and mineral, we assume that they are all isotropic materials. It is considered that the mineral is the ideal elastic-plastic, the postpeak strength will not decrease, while the coal matrix is elastic-plastic, and there is still some residual stress after the postpeak failure. In the strain-softening model, with the progress of loading, the basic mechanical parameters of the material will change due to softening when plastic deformation reaches the yield stage.

4.3. Modeling Boundary Conditions. In this paper, the finite element models were assigned boundary conditions to simulate the uniaxial and triaxial loading conditions. The nodes on the bottom surface of the model were fixed with 0 degrees of freedom, while the loaded surface nodes at the top were assigned a constant displacement along the compression direction. The same boundary conditions were applied at the top and bottom of the models in the confined compression test simulation and the confinement applied was $0.5,1,1.5$, and $2 \mathrm{MPa}$.

\section{Numerical Simulation and Analysis}

5.1. Failure Characterization of Model with Different Mineral Structures. The loading curve can confirm that the microstructure of coal controls both the stress and deformation mechanisms. Through the finite element analysis of the reconstruction models with different mineral structures, it was found that the size, volume, and spatial distribution of the mineral have a remarkable effect on the microscopic behavior (e.g., distribution of plastic zone and stresses), and the macroscopic behavior (e.g., stress-strain relationship and peak strength) of the heterogeneity coal. Figure 9 presents the full stress-strain curves of the three reconstruction models of coal with different mineral distributions under uniaxial compression. The changes in strength and brittleness of coal with different mineral structures under uniaxial compression can be seen in Figure 9. The simulation results further illustrate the response of mineral structure in coal to macroscopic mechanical behavior. 


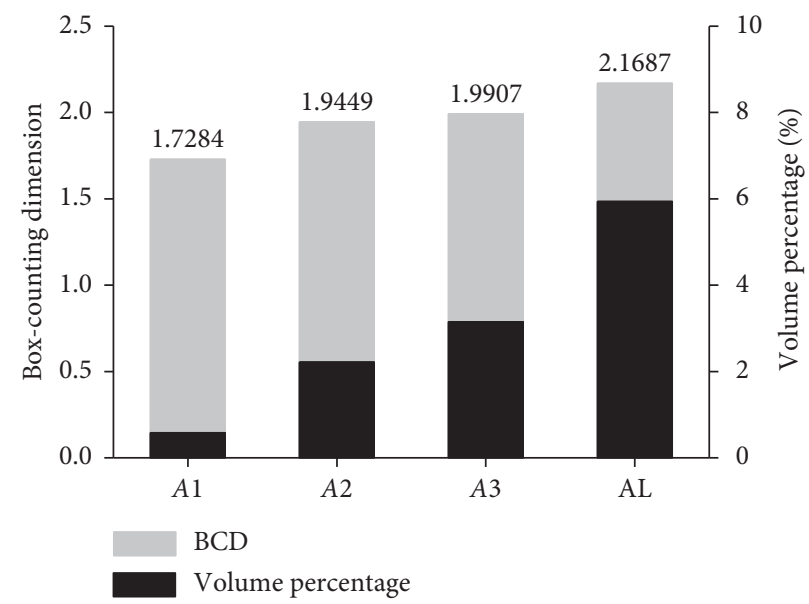

Figure 6: Quantitative characterization of mineral in coal.

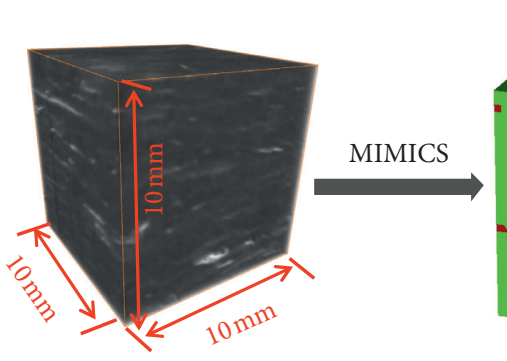

(a)

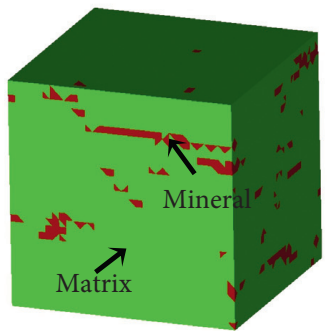

(b)

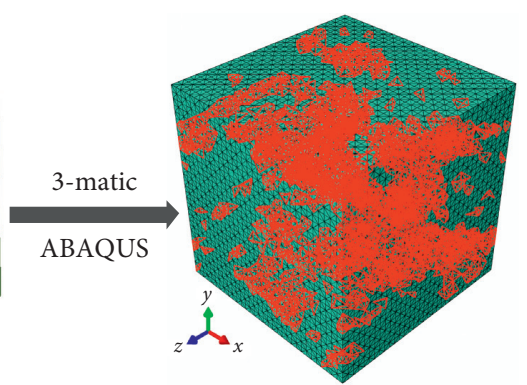

(c)

FIGURE 7: The reconstruction process schematic of the numerical model: (a) raw coal cube; (b) three-dimensional model reconstructed in the MIMICS; and (c) mesh model reconstructed in 3-matic and ABAQUS (the red part is mineral).

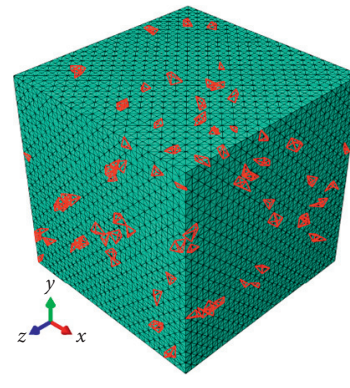

(a)

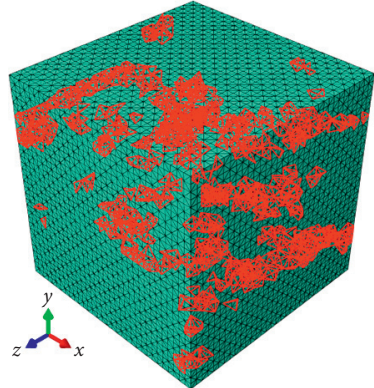

(b)

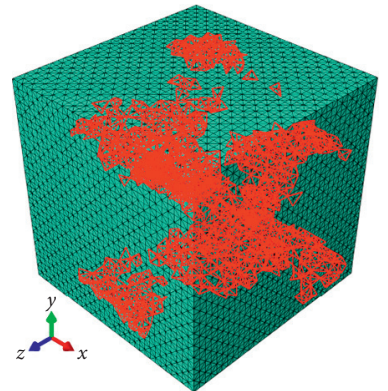

(c)

Figure 8: Mesh model in ABAQUS: (a) A1; (b) A2; and (c) $A 3$.

TABLE 2: The mechanical properties of the different materials used in the simulation.

\begin{tabular}{|c|c|c|c|c|c|c|}
\hline \multirow{2}{*}{ Property } & \multirow{2}{*}{ Young's modulus (MPa) } & \multirow{2}{*}{ Poisson's ratio } & \multicolumn{3}{|c|}{ Cohesion } & \multirow{2}{*}{ Friction angle $\left({ }^{\circ}\right)$} \\
\hline & & & Original value (MPa) & Softening rate $(\%)$ & Residual value (MPa) & \\
\hline Coal & 4000 & 0.33 & 1.13 & 0.2 & 0.113 & 40.6 \\
\hline Mineral & 26000 & 0.18 & 6.45 & - & - & 38.5 \\
\hline
\end{tabular}

According to the stress-strain curve in Figure 9, the elastic modulus, peak strength, and residual strength corresponding to different mineral distributions are obtained, and the results are shown in Figure 10. The simulation results show that the elastic modulus, peak strength, and residual strength increase monotonically from $A 1$ to $A 3$. Compared with $A 1$ and $A 2$, the size of the mineral structure in $A 3$ is larger, the distribution is more complex, and the elastic modulus, peak strength, and residual strength values are higher under uniaxial compression. 


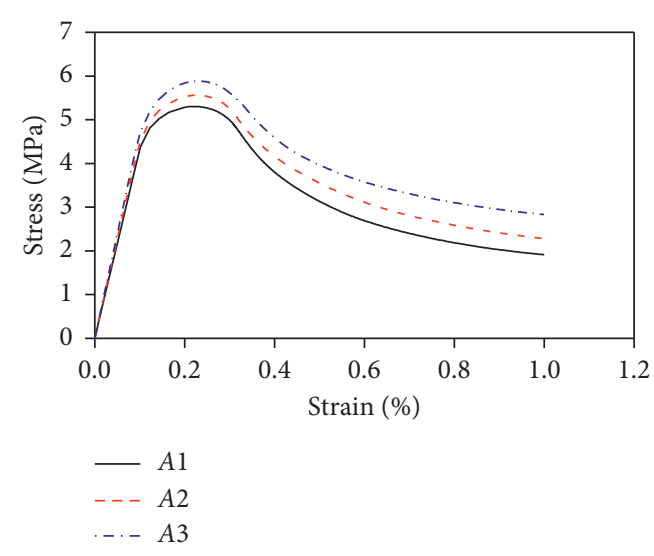

FIGURE 9: Simulated stress-strain curves for the coal under uniaxial compression.

In addition to influencing the stress-strain curve, minerals in coal have a great influence on the internal stress distribution, the location of failure, and the final failure pattern. In this paper, the uniaxial compression of the coal model with different mineral was carried out in the same loading method, and the stress contour and plastic zones of the failure process of each model was obtained, as shown in Figures 11-13. According to the nonlinear variations, three stages of simulation results are obtained from the full stressstrain curves, namely, the elastic stage $\left(60 \% \sigma_{\text {pre }-f}\right)$, the peak stage $\left(\sigma_{f}\right)$, and the postpeak stage $\left(75 \% \sigma_{\text {post }-f}\right)$, where, $60 \%$ $\sigma_{\text {pre- } f}, \sigma_{f}$, and $75 \% \sigma_{\text {post }-f}$, respectively, represent $60 \%$ peak stress before the peak, the peak stress, and $75 \%$ peak stress after the peak.

Based on the simulation results, the stress concentration is closely related to mineral distribution. It is apparent that stress concentrations occur at the location of the mineral distribution, as shown in Figures 11(b), 12(b), and 13(b). These localized stress concentrations are not uniformly distributed across the model and the area of the stress concentration region varies with the size of the mineral structure.

Figures 11(b), 12(b), and 13(b) show the stress distribution of models with different mineral; the result was obviously different. In model $A 1$, the stress distribution is uniform due to the small size of mineral while the stress distribution becomes more inhomogeneous in models $A 2$ and $A 3$ with the increase of mineral size and volume. This is due to the small mineral structure resulting in a smaller stress concentration area and having less effect on the stress distributions.

As shown in Figures 11(c), 12(c), and 13(c), in the elastic stages $\left(60 \% \sigma_{\text {pre- } f}\right)$, the plastic zones first occurred near mineral areas. This indicates that the initial cracks propagate around mineral in the elastic stage, which is consistent with the research by Gao et al. [5]. In the peak stage $\left(\sigma_{f}\right)$, the area of the plastic zones increases sharply, and the plastic strain concentration band begins to form. At this point, the plastic zone with a certain inclination angle is mainly caused by shear failure. In the postpeak stage $\left(75 \% \sigma_{\text {post }-f}\right)$, the plastic zones propagate and coalesce with each other, forming a macrofailure zone.

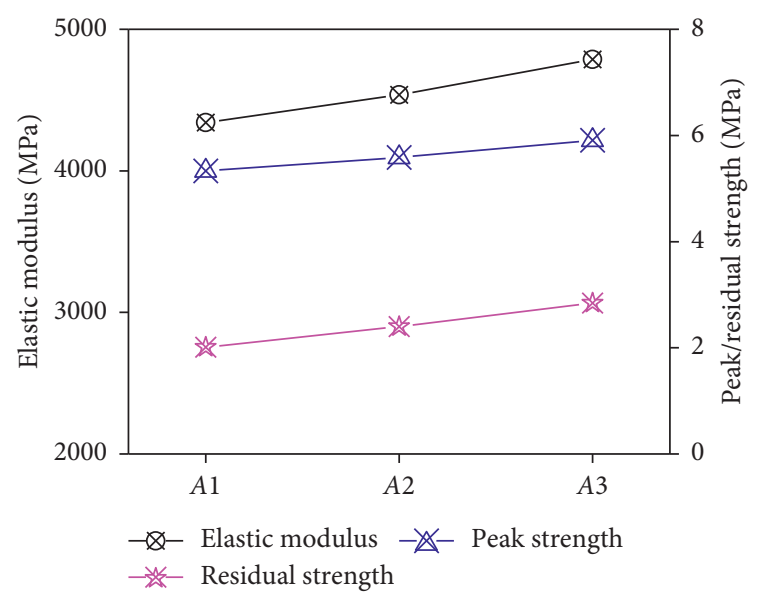

FIGURE 10: Elastic modulus, peak strength, and residual strength of coal.

The distribution of failure strips and stress concentration zones in model A1 is symmetrical at the peak stage $\left(\sigma_{f}\right)$, and the postpeak stage $\left(75 \% \sigma_{\text {post }-f}\right)$, as shown in Figures $11(\mathrm{~b})$ and 11(c). In model A3, the distribution of the plastic zones (failure strips) becomes more complex due to the larger mineral structure, as shown in Figures 13(b) and 13(c). This indicates that large mineral has a significant effect on stress distribution and macrofailure.

To compare with the experimental results, a heterogeneous model of coal with a larger mineral structure was selected for simulation. Figure 14 shows the results of the experiment and simulation. It can be seen from Figure 14(a) that the failure in coal occurs around the mineral interface, especially at the tip of the mineral structure. The simulation results show that the stress concentration occurs near the interface between mineral and matrix, and it is apparent that stress concentrations are higher on the mineral and lower on the coal matrix, as shown in Figure 14(b). The failure pattern of the model is indicated by the plastic zone distribution. Figure 14(c) shows the distribution of the failed zone (plastic elements) in the model; it can be seen that the plastic element is distributed on the interface of the two materials near the coal matrix, indicating that the distribution of the plastic zone is affected by the distribution of mineral structure. The above comparative analysis shows that the results of experiments and numerical simulations on the distribution of stress concentration and failure area are consistent.

\subsection{Effect of Mineral Structure on Coal Brittleness.}

Brittleness is one of the important mechanical properties of rock materials, and there is a direct correlation between mineral composition and brittleness $[26,27]$. The brittle failure of coal-rock is caused by the spatial distribution of mineral phases. The mineral is randomly formed and distributed within the coal, which consequently leads to the stress concentration and nonuniform distribution [4]. In order to study the effect of mineral structure on the macromechanical behavior of coal under confining pressure, a new brittleness index established by Ai et al. [28] was introduced. The new brittleness index is based on the energy 


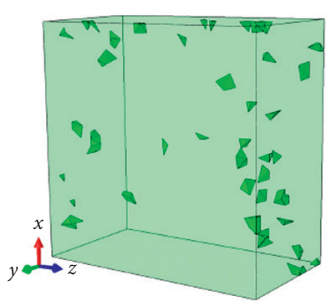

(a)

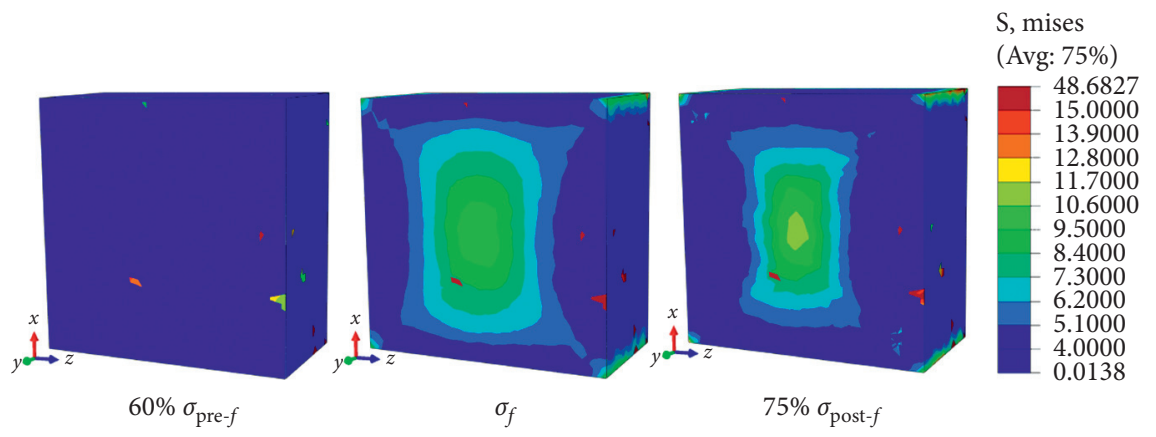

(b)
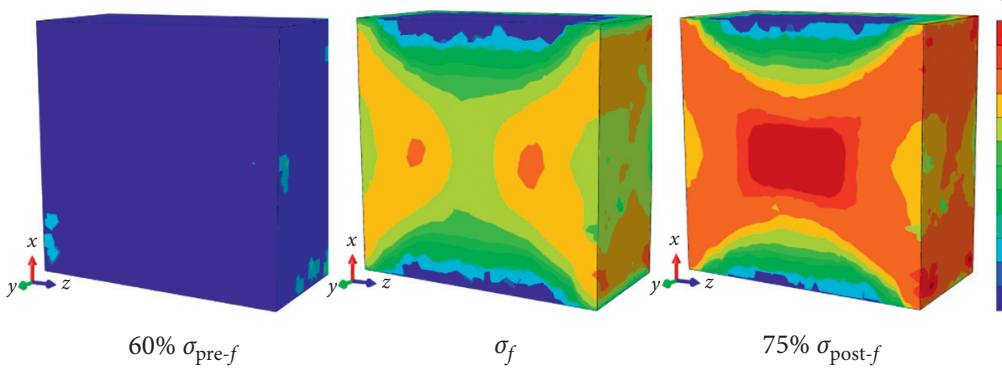

PEEQ

(Avg: $75 \%)$

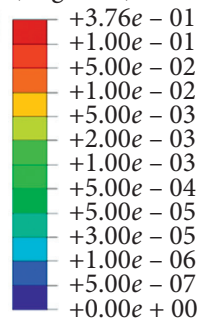

(c)

Figure 11: The distributions of mineral, the contours of the Mises stress, and plastic zones of $A 1$ at different loading moments: (a) sectional view of mineral distribution; (b) contour of Mises stress; and (c) distribution of plastic zones.

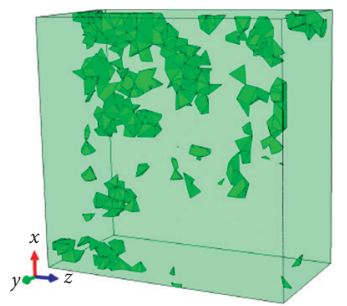

(a)

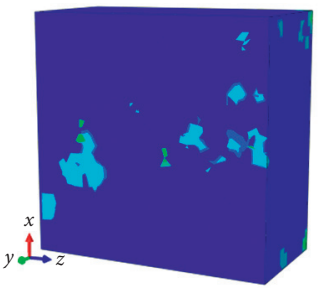

$60 \% \sigma_{\text {pre- } f}$
$60 \% \sigma_{\text {pre- } f}$

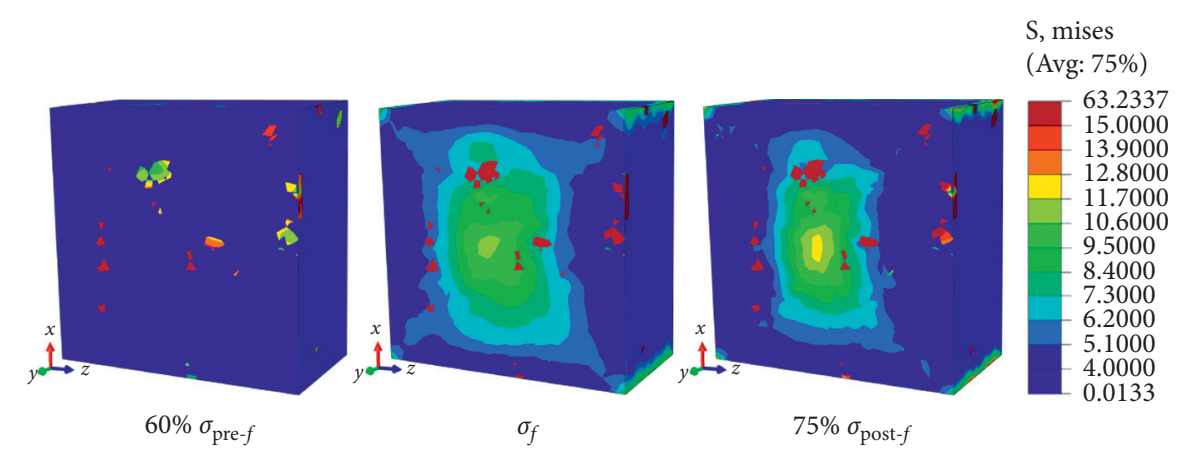

$75 \% \sigma_{\text {post }-f}$

(b)

PEEQ

(Avg: $75 \%)$

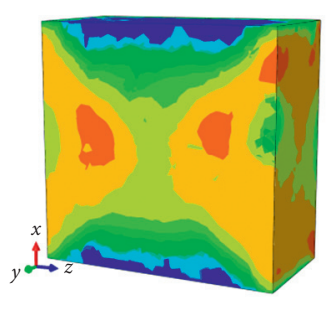

$\sigma_{f}$

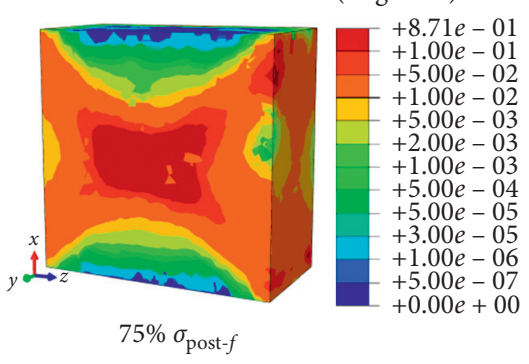

(c)

FIgURE 12: The distributions of mineral, the contours of the Mises stress, and plastic zones of $A 2$ at different loading moments: (a) sectional view of mineral distribution; (b) contour of Mises stress; and (c) distribution of plastic zones. 

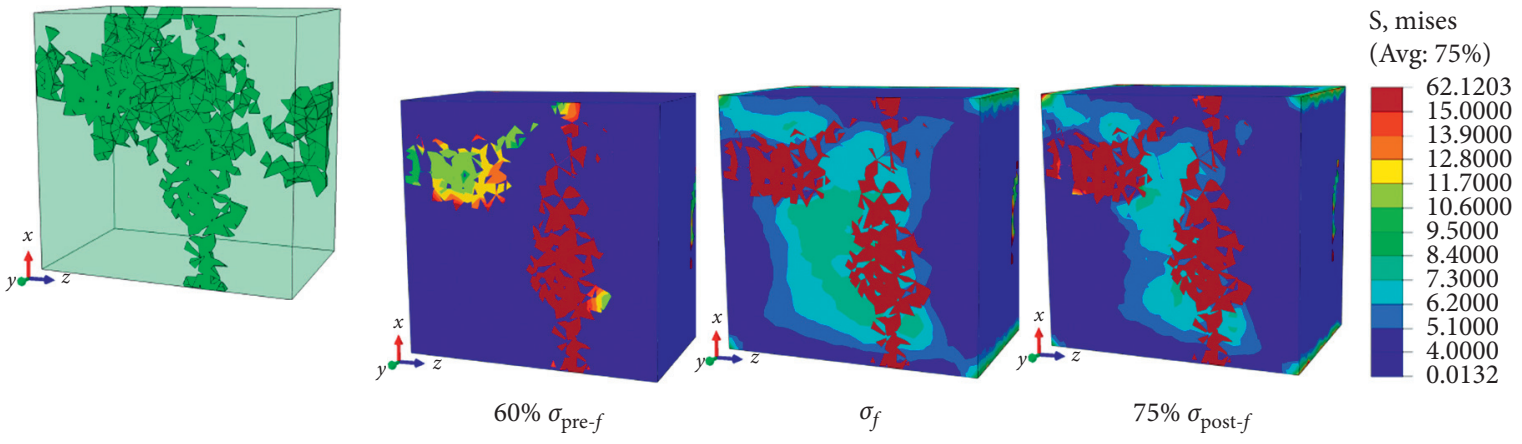

(a)

(b)

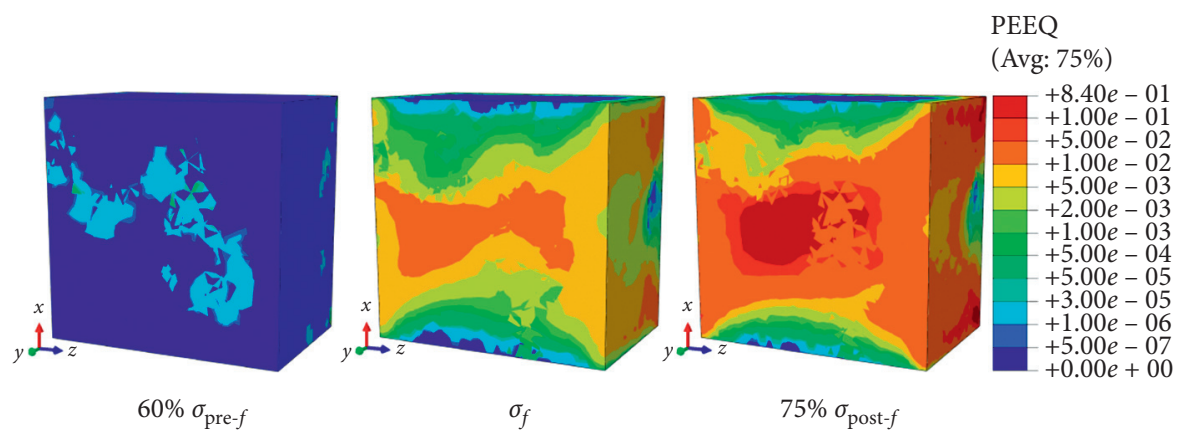

(c)

Figure 13: The distributions of mineral, the contours of the Mises stress, and plastic zones of $A 3$ at different loading moments: (a) sectional view of mineral distribution; (b) contour of Mises stress; and (c) distribution of plastic zones.

changes of stress-strain curves. The brittleness index is defined as follows:

$$
\begin{aligned}
W_{\mathrm{ue}} & =\frac{\sigma_{P}^{2}-\sigma_{R}^{2}}{2 E}, \\
W_{f} & =\frac{\left(\sigma_{P}^{2}-\sigma_{R}^{2}\right)(M-E)}{2 M E}, \\
W_{d} & =\int_{0}^{\varepsilon_{p}} \sigma_{i} d \varepsilon_{i}-\frac{\sigma_{P}^{2}}{2 E}, \\
B_{1} & =\frac{W_{f}+W_{d}}{W_{\mathrm{ue}}+W_{d}},
\end{aligned}
$$

where $\sigma_{P}, \sigma_{R}$, and $E$ are the peak strength, residual strength, and elastic modulus obtained based on the simulation. $M$ is the postpeak modulus; $W_{f}$ is the fracture energy; $W_{\text {ue }}$ is the unloading elastic energy; $W_{d}$ is the dissipation energy in the prepeak stage of the stress-strain curve; $\sigma_{i}$ represents the function of the prepeak curve; and $\varepsilon_{P}$ is the peak strain. $B 1$ represent the degrees of brittleness change from absolute ductility to absolute brittleness. The range of $B 1$ is $(0$, $+\infty$ ), where 0 is absolute brittleness and $\infty$ is absolute ductility. As illustrated in Figure 15, the postpeak modulus $M$ is negative and used to describe the postpeak stage of the stress-strain curve. The blue and pink areas represent, respectively, the dissipation energy of the prepeak stage and the fracture energy $\left(W_{f}\right)$. The gray area represents the unconsumed portion of energy and the area defined by the red dotted line in the diagram is elastic energy accumulated before the peak stress.

Figure 16 shows the stress-strain curves of models with three mineral structures under different confining pressures. It can be concluded from the complete curve that the peak strength and residual strength of the coal-rocks increase remarkably with the increase of confining pressure. When the confining pressure is the same, the peak strength of three different mineral structure models are different, and the magnitude relationship is $A 1<A 2<A 3$. It can also be seen that the postpeak softening responses exhibit high similarities for $A 1, A 2$, and $A 3$. The detailed calculation results are listed in Table 3.

In this paper, the brittleness of the coal heterogeneity model is calculated using indices $B 1$ under confining pressure. Table 2 lists the results of indices $B 1$. As illustrated in Figure 17, with an increase in confining pressure, the brittleness indices $B 1$ of coal increased. Under the same confining pressure, the brittleness index of $A 3$ is larger; that is, the ductility reaches its higher level. Compared with $A 1$ and $A 2$, the brittleness change of $A 3$ is less obvious with the increase of confining pressure. The results show that the existence of minerals in coal increases its ductility, and the influence becomes more obvious with the increase of mineral volume and complexity.

The correlations between the confining pressure and brittleness for the $A 1, A 2$, and $A 3$ were analysed based on the simulation results. The brittleness was plotted against the confining pressure as shown in Figure 18. The results show a good correlation between confining pressure and brittleness 


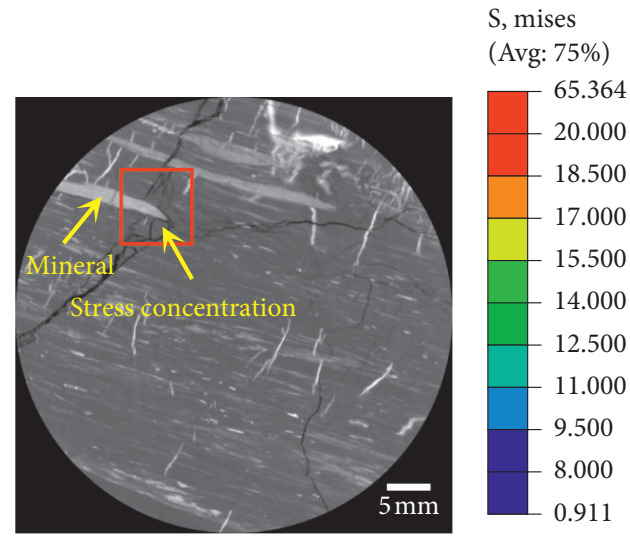

(a)

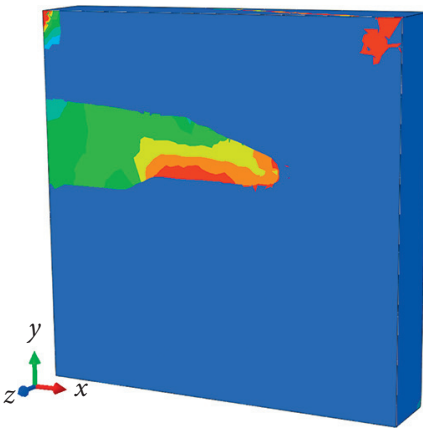

(b)

PE, max, principal (Avg: $75 \%$ )

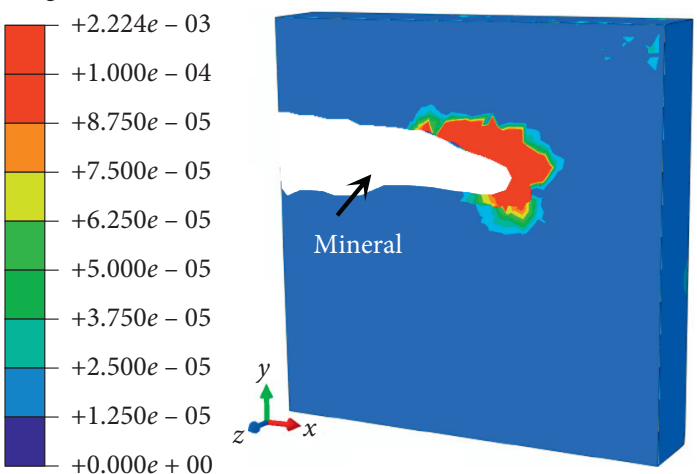

(c)

FIGURE 14: Stress distribution and failure characteristics of coal with mineral: (a) failure characteristics of uniaxial compression test; (b) distribution of stress concentration zones; and (c) distribution of plastic zones.

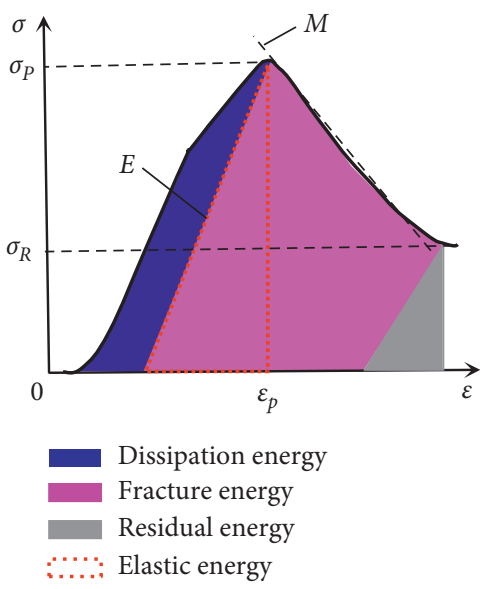

FIGURE 15: The schematic diagrams of energy conversion. 

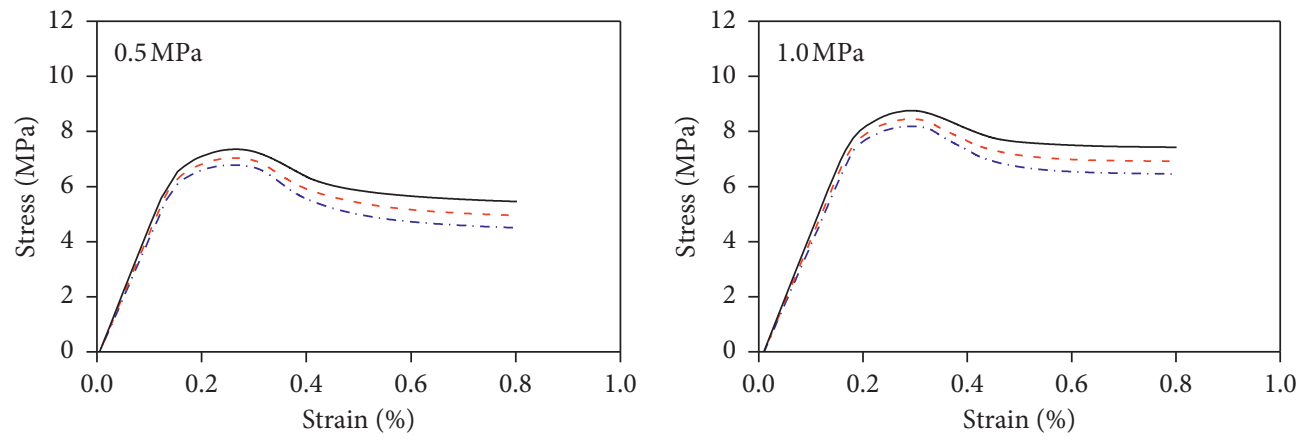

$$
\begin{array}{r}
-\cdot A 1 \\
---A 2 \\
-A 3
\end{array}
$$$$
\cdot-\cdot-A 1
$$$$
--A 2
$$$$
\text { - A3 }
$$

(a)

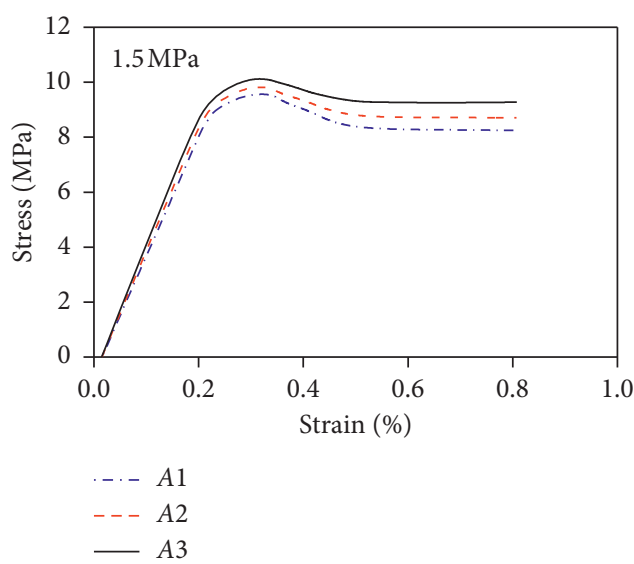

(c)

(d)

\begin{tabular}{|c|c|c|c|c|c|c|c|}
\hline $\begin{array}{l}\text { Compressing pressure } \\
(\mathrm{MPa})\end{array}$ & Number & $\begin{array}{c}\text { Peak strength } \\
(\mathrm{MPa})\end{array}$ & $\begin{array}{l}\text { Residual strength } \\
(\mathrm{MPa})\end{array}$ & $\begin{array}{c}\text { Elastic modulus } \\
(\mathrm{GPa}) \\
\end{array}$ & $\begin{array}{c}\text { Peak strain } \\
(\%)\end{array}$ & $\begin{array}{c}\text { Postpeak modulus } \\
(\mathrm{GPa})\end{array}$ & $B 1$ \\
\hline \multirow{3}{*}{0.5} & $A 1$ & 6.78 & 4.51 & 4.336 & 0.262 & -1.262 & 2.56 \\
\hline & $A 2$ & 7.04 & 4.96 & 4.537 & 0.263 & -1.135 & 2.68 \\
\hline & $A 3$ & 7.35 & 5.46 & 4.772 & 0.265 & -0.967 & 2.89 \\
\hline \multirow{3}{*}{1.0} & $A 1$ & 8.19 & 6.45 & 4.339 & 0.295 & -1.031 & 2.70 \\
\hline & $A 2$ & 8.45 & 6.92 & 4.535 & 0.293 & -0.881 & 2.88 \\
\hline & $A 3$ & 8.76 & 7.42 & 4.776 & 0.292 & -0.738 & 3.09 \\
\hline \multirow{3}{*}{1.5} & $A 1$ & 9.56 & 8.25 & 4.336 & 0.321 & -0.793 & 2.96 \\
\hline & $A 2$ & 9.82 & 8.72 & 4.526 & 0.318 & -0.681 & 3.08 \\
\hline & $A 3$ & 10.12 & 9.25 & 4.768 & 0.316 & -0.551 & 3.18 \\
\hline \multirow{3}{*}{2.0} & $A 1$ & 10.89 & 9.96 & 4.340 & 0.345 & -0.563 & 3.34 \\
\hline & $A 2$ & 11.15 & 10.39 & 4.541 & 0.342 & -0.467 & 3.41 \\
\hline & A3 & 11.44 & 10.93 & 4.762 & 0.339 & -0.342 & 3.48 \\
\hline
\end{tabular}

Figure 16: The stress-stain curves of coal models $A 1, A 2$, and $A 3$ : (a) $0.5 \mathrm{MPa}$; (b) $1.0 \mathrm{MPa}$; (c) $1.5 \mathrm{MPa}$; and (d) $2.0 \mathrm{MPa}$.

TABLE 3: Data of the triaxial compression simulation on coal.

${ }^{1} B 1$ : brittleness indices. 


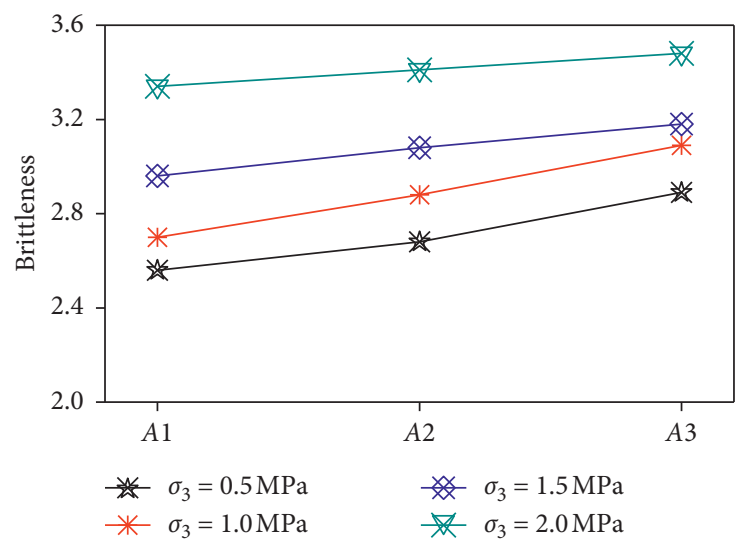

FIgURE 17: The brittleness of coal calculated using $B 1$.

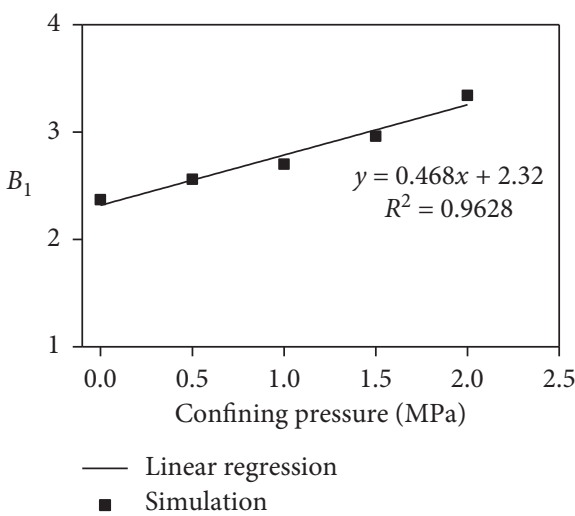

(a)

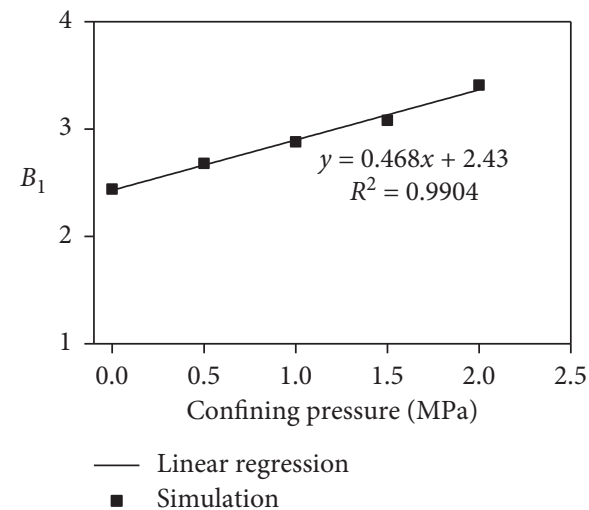

(b)

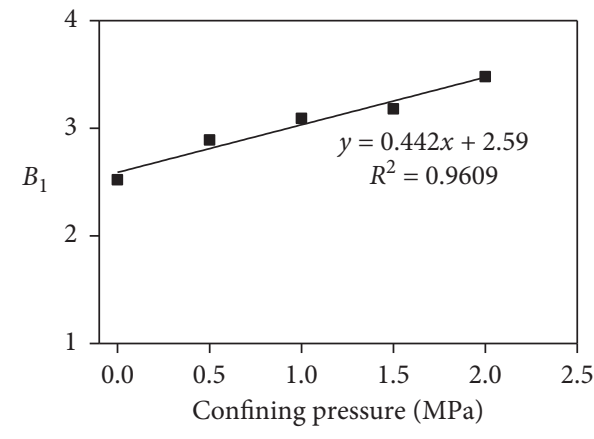

Linear regression

- Simulation

(c)

FIGURE 18: The relationship between the compressing pressure and $B 1$ : (a) $A 1$; (b) $A 2$; and (c) $A 3$.

index, the linear functions can be used to describe the relationship, and all have an $R^{2}$ exceeding 0.95 . The specific linear fitting relationship is shown in Figure 18.

\section{Conclusions}

This paper investigated the influence of microstructure on the macroscopic mechanical behavior of coal and mainly focuses on the influence of mineral structure size and distribution. The coal sample was scanned by an X-ray CT to obtain a digital coal body model. The mineral structure in the coal was quantitatively characterized by three-dimensional visualization software. Three numerical models with different mineral distribution characteristics were reconstructed in FEM simulations for analysis of the mechanical properties. The conclusions can be summarized as follows:

(1) The overall analysis of the mineral structure based on the equivalent diameter shows that there are a large 
number of mineral phases composed of different sizes and distributions in the coal, and the number of mineral structures decreases with the increase of equivalent diameter. The BCD of the original mineral structure in coal is greater than 2 and less than 3 in $3 \mathrm{D}$ space. The mineral is divided into several parts according to the size by the sieving principle, and the fractal box dimension of each part is less than 2 .

(2) Under uniaxial conditions, the presence of minerals increases the peak strength, elastic modulus, and residual strength of coal, and the larger the size of the mineral is, the more complex the distribution is, and the more the strength and elastic modulus increase.

(3) The mineral structure in coal may result in uneven distribution of internal stress. There is obvious stress concentration in the location of minerals, and the area of stress concentration at the location of the mineral is related to the size of the mineral structure. The failure (plasticity) first occurred at the interface between the matrix and the mineral. With the increase of the size of the mineral structure, the influence on the failure form of coal is more obvious.

(4) Under confining pressure, the mineral structure of coal has an obvious influence on its brittleness. The presence of mineral decreases the brittleness of the coal. The larger the size of the mineral structure and the more complex the distribution, the weaker the brittleness of the coal. The relation between confining pressure and brittleness index is fitted by a linear function, and the correlation coefficient $\left(R^{2}\right)$ exceeds 0.95 , indicating that there is a good linear relationship between the two.

\section{Data Availability}

The data used to support the findings of this study are available from the corresponding author upon request.

\section{Conflicts of Interest}

The authors declare that there are no conflicts of interest regarding the publication of this study.

\section{Acknowledgments}

This project was financially supported by the National Key Research and Development Program (Grant no. 2016YFC0600901) and National Natural Science Foundation of China (no. 11572344).

\section{References}

[1] G. Zhou, Q. Zhang, R. Bai, and G. Ni, "Characterization of coal micro-pore structure and simulation on the seepage rules of low-pressure water based on CT scanning data," Minerals, vol. 6, no. 3, p. 78, 2016.

[2] Y. Yao, D. Liu, Y. Che, D. Tang, S. Tang, and W. Huang, "Nondestructive characterization of coal samples from China using microfocus X-ray computed tomography," International Journal of Coal Geology, vol. 80, no. 2, pp. 113-123, 2009.

[3] K. Zheng, B. Qiu, Z. Wang, J. Li, and K. Gao, "Modelling heterogeneous coal-rock (HCR) failure patterns under dynamic impact loads using image-based finite element (FE) and discrete element (DE) model," Powder Technology, vol. 360, pp. 673-682, 2020.

[4] Y. Zhao, H. Song, S. Liu et al., "Mechanical anisotropy of coal with considerations of realistic microstructures and external loading directions," International Journal of Rock Mechanics and Mining Sciences, vol. 116, pp. 111-121, 2019.

[5] F. Gao, H. Kang, and Y. Wu, "Experimental and numerical study on the effect of calcite on the mechanical behaviour of coal," International Journal of Coal Geology, vol. 158, pp. 119-128, 2016.

[6] P. Ranut, E. Nobile, L. Mancini, and F. Science, "High resolution X-ray microtomography-based CFD simulation for the characterization of flow permeability and effective thermal conductivity of aluminum metal foams," Experimental Thermal and Fluid Science, vol. 67, pp. 30-36, 2015.

[7] B. Van Belleghem, R. Montoya, J. Dewanckele et al., "Capillary water absorption in cracked and uncracked mortar-a comparison between experimental study and finite element analysis," Construction and Building Materials, vol. 110, pp. 154-162, 2016.

[8] C. Puncreobutr, A. B. Phillion, J. L. Fife, and P. D. Lee, "Coupling in situ synchrotron X-ray tomographic microscopy and numerical simulation to quantify the influence of intermetallic formation on permeability in aluminium-siliconcopper alloys," Acta Materialia, vol. 64, pp. 316-325, 2014.

[9] M. Van Geet, R. Swennen, and P. David, "Quantitative coal characterisation by means of microfocus X-ray computer tomography, colour image analysis and back-scattered scanning electron microscopy," International Journal of Coal Geology, vol. 46, no. 1, pp. 11-25, 2001.

[10] F. J. Simons, F. De'Ric Verhelst, and R. Swennen, "Quantitative characterization of coal by means of microfocal X-ray computed microtomography (CMT) and color image analysis (CIA)," International Journal of Coal Geology, vol. 34, no. 1-2, pp. 69-88, 1997.

[11] S. Mazumder, K.-H. Wolf, K. Elewaut, and R. Ephraim, "Application of X-ray computed tomography for analyzing cleat spacing and cleat aperture in coal samples," International Journal of Coal Geology, vol. 68, no. 3-4, pp. 205-222, 2006.

[12] A. Golab, C. R. Ward, A. Permana, P. Lennox, and P. Botha, "High-resolution three-dimensional imaging of coal using microfocus X-ray computed tomography, with special reference to modes of mineral occurrence," International Journal of Coal Geology, vol. 113, pp. 97-108, 2013.

[13] J. P. Mathews, Q. P. Campbell, H. Xu, and P. Halleck, “A review of the application of X-ray computed tomography to the study of coal," Fuel, vol. 209, pp. 10-24, 2017.

[14] J. P. Mathews, J. D. N. Pone, G. D. Mitchell, and P. Halleck, "High-resolution X-ray computed tomography observations of the thermal drying of lump-sized subbituminous coal," Fuel Processing Technology, vol. 92, no. 1, pp. 58-64, 2011.

[15] N. Tsafnat, N. Amanat, and A. S. Jones, "Analysis of coke under compressive loading: a combined approach using micro-computed tomography, finite element analysis, and empirical models of porous structures," Fuel, vol. 90, no. 1, pp. 384-388, 2011.

[16] C. Sandino, J. A. Planell, and D. Lacroix, “A finite element study of mechanical stimuli in scaffolds for bone tissue 
engineering," Journal of Biomechanics, vol. 41, no. 5, pp. 1005-1014, 2008.

[17] W.-J. Xu, Z.-Q. Yue, R.-L. Hu, and M. Sciences, "Study on the mesostructure and mesomechanical characteristics of the soilrock mixture using digital image processing based finite element method," International Journal of Rock Mechanics and Mining Sciences, vol. 45, no. 5, pp. 749-762, 2008.

[18] Y. Huang, Z. Yang, W. Ren, G. Liu, and C. Zhang, "3D mesoscale fracture modelling and validation of concrete based on in-situ X-ray Computed Tomography images using damage plasticity model," International Journal of Solids and Structures, vol. 67-68, pp. 340-352, 2015.

[19] Z. Q. Yue, S. Chen, and L. G. Tham, "Finite element modeling of geomaterials using digital image processing," Computers and Geotechnics, vol. 30, no. 5, pp. 375-397, 2003.

[20] Y. Zhang and M. N. Toksöz, "Impact of the cracks lost in the imaging process on computing linear elastic properties from 3D microtomographic images of Berea sandstone," Geophysics, vol. 77, no. 2, pp. R95-R104, 2012.

[21] P. L. Rosin, "Unimodal thresholding," Pattern Recognition, vol. 34, no. 11, pp. 2083-2096, 2001.

[22] B. J. N. Mandelbrot, The Fractal Geometry of Nature, pp. 394-397, W. H. Freeman and Co., New York, NY, USA, 1990.

[23] A.-L. Barabási and H. E. Stanley, Fractal Concepts in Surface Growth, Cambridge University Press, Cambridge, UK, 1995.

[24] J. Li, Q. Du, and C. Sun, "An improved box-counting method for image fractal dimension estimation," Pattern Recognition, vol. 42, no. 11, pp. 2460-2469, 2009.

[25] Y. Zhao, S. Liu, G.-F. Zhao, D. Elsworth, Y. Jiang, and J. Han, "Failure mechanisms in coal: dependence on strain rate and microstructure," Journal of Geophysical Research: Solid Earth, vol. 119, no. 9, pp. 6924-6935, 2014.

[26] R. Altindag and A. J. S. R. Guney, "Predicting the relationships between brittleness and mechanical properties (UCS, TS and $\mathrm{SH}$ ) of rocks," Scientific Research and Essays, vol. 5, no. 16, pp. 2107-2118, 2010.

[27] R. Mikaeil, M. Ataei, and R. Yousefi, "Correlation of production rate of ornamental stone with rock brittleness indexes," Arabian Journal of Geosciences, vol. 6, no. 1, pp. 115-121, 2013.

[28] C. Ai, J. Zhang, Y.-W. Li et al., "Estimation criteria for rock brittleness based on energy analysis during the rupturing process," Rock Mechanics and Rock Engineering, vol. 49, no. 12, pp. 4681-4698, 2016. 